\title{
POPULAÇÕES TRADICIONAIS, AÇÃO COMUNITÁRIA, CAPITAL SOCIAL E EDUCAÇÃO: UM DEBATE NECESSÁRIO À EFETIVAÇÃO DE RESERVAS EXTRATIVISTAS NA AMAZÔNIA
}

\author{
José Bittencourt da SILVA \\ ICED/UFPA \\ jbsilva@ufpa.br
}

Resumo: Uma população tradicional é aquela que apresenta, pelo menos em parte, uma história de baixo impacto ambiental e que tem no presente interesse em manter ou em recuperar o controle sobre o território em que vive. $O$ objetivo deste artigo é tecer reflexões acerca dessas populações, buscando expor suas mais prementes dificuldades, como a dificuldade em agir em comunidade e o problema do baixo capital social no contexto das reservas extrativistas (RESEX) amazônicas. Neste contexto, coloca-se o paradigma da educação do campo como uma proposta alternativa ao que se vem realizando hegemonicamente nas escolas locais, e em particular o caso da RESEX Ipaú-Anilzinho, no município de Baião, estado do Pará. Do ponto de vista metodológico, o trabalho configura-se como o resultado de uma pesquisa bibliográfica, realizada em bibliotecas fisicas, virtuais e em acervo pessoal. O que segue são aprofundamentos acerca da temática indicada a partir da literatura examinada.

Palavras-chave: População tradicional. Agir em comunidade. Capital social. Educação do campo.

Abstract: Theoretically, a traditional population has, at least in part, a history of low environmental impact, and has in the present interest in maintaining or obtain the control over the territory that inhabit. The aim of this paper is to make reflections about these populations, objecting to expose and talk about their most important problems, such as the difficulty to work in community and the problem of low social capital in the context of extractive reserves (RESEX) in the Amazon. In this context, the paradigm of education of the field is an alternative to authoritarian model education in the RESEXs, especially in the RESEX Ipau-Anilzinho, Para state. Methodologically, this paper result of a literature search made in the libraries physical and virtual, and personal collection. What follows are discussions about the subject indicated, from the literature examined.

Keywords: Traditional population. Action in community. Social capital. Education of the field.

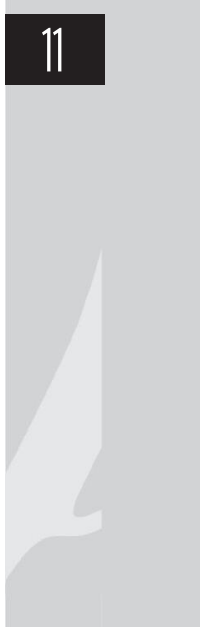




\section{Introdução}

O conceito de população tradicional é bastante abrangente, pois seu conteúdo real engloba, por exemplo, desde os coletores de berbigão de Santa Catarina, passando pelas babaçueiras do sul do Maranhão, até as quilombolas do Tocantins. Apesar da perspectiva generalizante, é possível definir essas populações a partir de autores como Balée (1989), Diegues (1996; 1993), Roué (1997), Simonian (2003) e outros. Para estes, o que caracteriza dado grupo social como tradicional é a relação entre seu modo de vida e a sustentabilidade dos ecossistemas nos quais estão inseridos. Nesta linha de pensamento, Posey (1997) observa que as populações tradicionais foram (e ainda são) fundamentais, não só para a manutenção da biodiversidade na Amazônia e alhures, mas também para o melhoramento das espécies vegetais.

Diegues (2001 apud GUERRA; COELHO, 2009, p. 29), com base em dois casos observados na África, exemplifica a relação entre o modo de vida de populações tradicionais e a manutenção ecossistêmica da natureza.

[...] As práticas culturais de manejo dos recursos naturais desenvolvidas por algumas dessas populações interagem com o processo evolutivo das espécies há milhares de anos, de modo que a presença das populações e o manejo que fazem de determinados ecossistemas são essenciais à manutenção da biodiversidade. O caso dos maasai é um exemplo, pois a implantação de parques e a retirada desse povo que manejava a paisagem de savana em regiões da Tanzânia e do Quênia, com queimadas periódicas, levaram à continuidade do processo de sucessão ecológica, de modo que áreas anteriormente cobertas por herbáceas passaram a ser dominadas por arbustos, com redução nas populações de grandes mamíferos. (Diegues 2001 apud GUERRA; COELHO, 2009, p. 29).

Simonian (2003) cita também os castanhais amazônicos como exemplo marcante da ação positiva das populações tradicionais sobre os ecossistemas naturais. Neste sentido, uma definição bastante plausível apresenta uma população tradicional como aquela que, pelo menos em parte, possui “[...] uma história de baixo impacto ambiental e de que têm 
no presente interesse em manter ou em recuperar o controle sobre o território que exploram" (CUNHA; ALMEIDA, 1999, p. 184).

No processo atual de busca por um desenvolvimento social e/ou comunitário próprio na Amazônia, essas populações enfrentam grandes dificuldades para efetivar projetos de melhoria coletiva de vida. Tais melhorias englobam o controle do território e a sustentabilidade do modus vivendi das famílias locais, segurança fundiária e alimentar, saúde e educação de qualidade. Em grande medida, isso se dá porque não há políticas públicas voltadas à qualificação dessas pessoas, historicamente ligadas ao patronato, clientelismo e favorecimento individual próprios do sistema de aviamento. Por estarem mergulhadas nesse caldo histórico, possuem baixo capital social e apresentam extrema dificuldade para formação de redes de confiança e solidariedade para além da família nuclear. Isso tem rebatimentos negativos diretos na criação, desenvolvimento e gerenciamento de associações comunitárias ou cooperativas.

No contexto da busca por alternativas para suplantar as vicissitudes específicas das populações tradicionais, tem-se a educação escolar. Todavia, faz-se mister rever por completo o paradigma vigente de educação dominante, o qual se baseia na disciplinaridade, compartimentalização dos conteúdos, separação entre ciência e saber popular e tantas outras dicotomias preconceituosas da era moderna. No lugar desse modelo educacional, precisa-se implementar uma nova proposta de escola que garanta a construção de um indivíduo completo, aquele que estuda, trabalha, respeita as diferenças e os ecossistemas naturais, percebendo-se como agente produtor de sua realidade.

O objetivo deste artigo é tecer reflexões acerca das populações tradicionais, buscando expor e debater seus problemas, como a dificuldade em agir em comunidade e o baixo capital social. Para tanto, o trabalho foi dividido em três momentos, a saber: primeiro, uma breve conceituação sobre o sentido e o significado do conceito de população tradicional; posteriormente, apresentam-se algumas das questões que precisam ser superadas por elas, como a incapacidade que essas populações possuem para agir segundo a formalidade da lei e a extrema dificuldade em formar redes de confiança e solidariedade, e, por extensão, em efetivar suas associações e cooperativas. Como último momento do artigo tem-se uma perspectiva mais analítico-propositiva, ou seja, buscou-se demonstrar 
a importância da educação escolar como elemento fundante para as possíveis saídas para essas vicissitudes observadas.

Neste contexto, coloca-se o paradigma da educação do campo como uma proposta alternativa ao que se vem realizando hegemonicamente nas escolas das RESEX amazônicas, e, em particular, nas paraenses, em que se pode citar o caso da RESEX Ipaú-Anilzinho, no município de Baião. Mais do que em qualquer outro lugar, nesta Unidade de Conservação (UC), a educação escolar deveria contribuir para o fim do analfabetismo, para o aumento da escolaridade e, acima de tudo, para capacitar as pessoas, visando a uma efetiva participação comunitária, na busca da equidade social e respeito ao meio ambiente. Mas, o que se observa é a efetivação de uma escolarização metafísica, urbanocêntrica e compensatória.

Do ponto de vista metodológico, o trabalho configura-se como o resultado de uma pesquisa bibliográfica (CARVALHO, 1995; SANTOS, 2001; SEVERINO, 2007), realizada em biblioteca física, virtual e acervo pessoal. Para a exposição conceitual acerca das populações tradicionais e as RESEX, podem-se citar os seguintes autores: Balée (1989), Cunha e Almeida (1999), Guerra e Coelho (2009), Roué (1997), Silva (2003a; 2007; 2010) e Simonian, (2000; 2003). O conceito de ação comunitária e capital social tem nos trabalhos de Weber (1993), Putnam (1996) e Ostrom (1998) seus principais autores. Quanto à questão da educação escolar, a base de referência para as arguições levantadas são as obras de Freire $(1983 ; 2001 ; 2004)$ e Gadotti $(2008)$. O que segue são aprofundamentos acerca da temática indicada a partir da literatura examinada.

\section{Populações tradicionais, ação comunitária, capital social e educação: um debate necessário à efetivação de Reservas Extrativistas na Amazônia}

Considera-se como população tradicional aquela que se baseia em sistemas sustentáveis de exploração dos recursos naturais, desenvolvidos ao longo de gerações e adaptados às condições ecológicas locais. $\mathrm{Na}$ Amazônia, essas populações demonstraram ser fundamentais na proteção, enriquecimento e manutenção da diversidade biológica. Os grupos humanos mais representativos desse conceito são as populações indígenas, extrativistas (castanheiros, seringueiros, balateiros etc.), ribeirinhos $\mathrm{e}$ 
quilombolas. Balée (1989), Guerra e Coelho (2009), Posey (1997), Roué (1997), Silva (2010) e Simonian (2003) afirmam que as práticas culturais e de manejo florestal desses grupos humanos interagem com o processo evolutivo das espécies, de modo que a presença dessas pessoas e a maneira como elas utilizam determinados ecossistemas é essencial à conservação da biodiversidade local.

No contexto da criação das Áreas Protegidas e Unidades de Conservação (UC) brasileiras, o Estado, em seus níveis federal, estadual e municipal, vem institucionalizando essas populações tradicionais e enquadrando-as em práticas baseadas em estatutos formalmente estabelecidos. Particularmente, as Reservas Extrativistas (RESEX) e as populações residentes em seus limites estão hoje colocadas em uma estrutura racional-legal, na qual as relações com o meio ambiente natural e social devem estar calcadas naquilo que Weber (1993) denominou de ação comunitária. Todavia, percebe-se que não houve o devido preparo dessas populações tradicionais para que possam atuar dentro dos rituais protocolares próprios da formalidade estatal.

Uma ação comunitária é aquela em que o indivíduo age inserido em uma dada organização social com regras, papéis e objetivos bem definidos, ou seja, é uma ação que possui uma íntima relação com fins determinados pela regulação estatutária (WEBER, 1993). Esse tipo de conduta é típico das associações modernas (públicas ou privadas), na qual o comportamento de cada pessoa deve estar balizado por uma ética racionalmente estipulada, que Weber (1993, p. 314) conceituou como ação racional com relação afim, “[...] que se orienta, exclusivamente, por meios tidos por adequados (subjetivamente) para obter fins determinados, tidos por indiscutíveis (subjetivamente)".

Weber (1993) alerta para o fato de que é evidente que muitas pessoas agem contrariamente ao que expressa suas organizações ou às regras do jogo. Contudo, deve-se notar que existe uma média no agir comunitário aceito comumente pelos participantes do grupo. Assim sendo, as ações em comunidade, contrárias à ordem estabelecida e que se afastam da média da interpretação da coletividade, devem ser vistas como um agir em comunidade objetivamente "anormal" (Weber, 1992, p. 327). Seguindo esta linha de raciocínio, pode-se colocar a deserção, a busca de 
interesses particulares, a falta de sentimento coletivo, o individualismo etc. como práticas não comunitárias, as quais põem em risco os objetivos grupais, qual seja: o bem comum de seus participantes.

Silva $(2003 a$; 2007) vem mostrando as dificuldades de se efetivar os objetivos coletivos das populações tradicionais nas RESEX via associação social ou empresas cooperadas, ou seja, dentro de estruturas que exigem uma ação comunitária. Um dos argumentos-chave de suas assertivas reside no fato de que as populações tradicionais não possuem tradição para implementar processos formais de gestão organizacional, afinal o cotidiano institucional necessita de reuniões, de gestão de conflitos, de produção de atas, relatórios, balanços contábeis, tudo balizado pelo estatuto regulador das ações em comunidade, realidade extremamente nova e historicamente distante do modo de vida desses sujeitos sociais da Amazônia.

Para além desses entraves próprios da racionalidade formal das instituições, o autor também afirma que existe um sério dilema no contexto do desenvolvimento das RESEX amazônicas a ser enfrentado. Se por um lado as populações tradicionais efetivam cotidianamente formas produtivas e simbólicas ecologicamente importantes; por outro, suas práticas políticas estão mergulhadas em um caldo histórico herdado do sistema de aviamento, fortemente calcado no individualismo, no favorecimento familiar e no baixo capital social, este último indispensável à sustentabilidade organizacional de qualquer formação societária na atualidade e, em consequência, ao desenvolvimento local.

O debate acerca do capital social no contexto da ação comunitária tem sido colocado como uma saída ao agir em sociedade objetivamente "anormal". Ou seja, se por um lado o capital social facilita as ações coordenadas por meio das redes de confiança e solidariedade, tornando mais eficiente a sociedade e o Estado, por outro, como mostram Putnam (1996) e Ostrom (1998), pode solucionar os dilemas da ação coletiva e do oportunismo contraproducente daí resultante. Precisamente, as discussões sobre capital social partem do pressuposto básico de que este tipo de capital é um componente necessário ao desenvolvimento, e mais do que isso, ele melhora as interações sociais e promove uma redução do individualismo no âmbito da ação social ou comunitária.

A fonte conceitual basilar das discussões acerca do capital social pode ser buscada em pensadores que construíram a concepção moderna 
de sociedade civil e de Estado. Inclusos nesse rol estão pesadores liberais, democratas e socialistas, cada um ressaltando aspectos importantes segundo seus paradigmas de análise. Precisamente, pensadores como Thomas Hobbes, David Hüme, John Locke, Jean Jacques Rousseau e, principalmente, Hegel e Alexis Tocqueville podem ser colocados como autores paradigmáticos do debate moderno sobre capital social. Aliás, Tocqueville vem sendo bastante citado em obras de autores contemporâneos como Abramovay (2000), Coleman (1990), Putnam (1996), Rattner (2002), Woolcock (1998) entre outros estudiosos do tema.

Tocqueville ([1835] 1987) colocou, de maneira bastante clara, a ideia matriz de que o associativismo nos Estados Unidos constituiuse no pilar da democracia americana. E mais do que isso, as associações civis são apontadas por este pensador como fator essencial para a eficácia e a estabilidade do governo, bem como formaram nos cidadãos americanos hábitos de cooperação, solidariedade e espírito público. As associações também são tidas por ele como a condição da autonomia dos indivíduos, que "[...] somente recorrem ao poder estatal quando não podem passar sem ele" (TOCQUEVILLE, [1835] 1987, p. 146). Esta concepção tocquevilleana da relação entre sociedade civil e os indivíduos vai de encontro ao ideário hobbesiano, que propõe claramente um fortalecimento da ação do Estado em frente dos problemas gerados interpessoalmente.

É bastante elucidativa a periodização feita por D'Araujo (2003) acerca da utilização conceitual de capital social. Para esta autora, o termo, tal qual se conhece hoje, foi utilizado pela primeira vez em 1916, por Lyda Judson Hanifan, que

[...] usou o conceito para descrever centros comunitários de escolas rurais, nas quais detectava que a pobreza crescente se fazia acompanhar pelo decréscimo da sociabilidade e das relações de vizinhança entre a população local (D'ARAUJO, 2003, p. 23-24).

A autora segue periodizando o conceito, mostrando sua utilização pelo canadense John Seeley, em 1950; na década seguinte pela norteamericana Jane Jacobs em sua obra The death and life of great american cities; nos anos de 1970, pelo economista Glenn Loury e pelo sociólogo Ivan

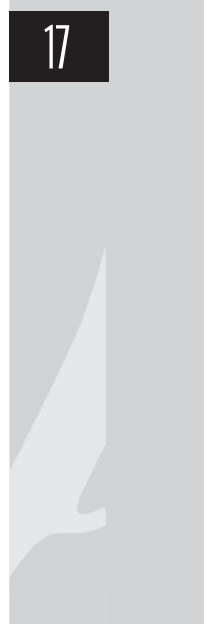


Light e seus estudos sobre desenvolvimento econômico nos Estados Unidos; e chega à década de 1980 sendo bastante utilizado. Na França, pelo sociólogo Pierre Bourdieu; na Alemanha, pelo economista Ekehart Schlicht; na América, pelo sociólogo James Coleman.

É nos anos de 1980 que o conceito entra definitivamente na agenda acadêmica. Talvez a obra mais importante neste sentido, a qual deu notoriedade ao conceito de capital social, tenha sido o livro de Robert Putnam Making democracy work: civic traditions in Modern Italy, que foi traduzido para o português com o título: Comunidade e democracia: a experiência da Itália moderna. Apesar de bastante recente, esta obra de Putnam já se tornou um clássico nas Ciências Sociais, o que não a exime de críticas, principalmente acerca de seu caráter determinista. Para Putnam (1996), capital social refere-se ao conjunto de normas de confiança mútua, às redes de cooperação, aos mecanismos de sanção e às regras de comportamento que podem melhorar a eficácia da sociedade, na solução de problemas que exigem a ação coletiva. Visto como um bem de todos, este capital é gerado a partir das práticas cotidianas institucionais.

Pode-se dizer que, para Putnam (1996), o capital social é edificado, ensinado e apreendido em um processo educativo que se implementa no dia a dia das chamadas organizações horizontais, aquelas que não possuem estruturas hierárquicas rígidas e centralizadas. Como exemplo dessa horizontalidade organizacional, o autor apresenta os clubes desportivos, as cooperativas, sociedades de mútua assistência, associações culturais e sindicatos. Os indivíduos participantes dessas associações criam redes de confiança e de compromisso, constroem vínculos de reciprocidade, de cooperação e de solidariedade capazes de estimular normas e condutas individuais com fins coletivos, suscetíveis de aumentar o desenvolvimento humano, social e econômico de um dado agrupamento societário.

O exemplo mais emblemático de uma prática social que cria e fortalece o capital social é a chamada associação de crédito rotativo ${ }^{1}$. Para Putnam (1996, p. 177), “[...] as associações de crédito rotativo variam bastante em tamanho, composição social, organização e critérios para

\footnotetext{
${ }^{1}$ Localmente chamada de "caixinha", esse tipo de associação consiste em um grupo de pessoas que se comprometem em contribuir regularmente com uma soma em dinheiro, formando um fundo destinado e acessado por cada contribuinte de maneira alternada. Nesta prática societária, o fundamento das relações entre os participantes é exatamente a confiança mútua e a solidariedade entre os participantes.
} 
determinar as contribuições. Todas elas combinam sociabilidade com formação de capital em pequena escala”. Desse modo, estas associações, muito mais do que uma maneira de garantir rendimentos materiais para seus membros, podem se constituir em organizações coletivas estruturantes de valores e normas de solidariedade e confiança entre seus membros participantes. Do ponto de vista macro, esses valores podem ter rebatimentos positivos, quando se trata de resolver problemas públicos mais gerais ou coletivos.

Portanto, as relações estruturantes em escala micro, ou face a face, como quer Ostrom (1998), são formadoras de confiança recíproca e de sentimentos coletivos, os quais tornam a transgressão uma prática arriscada entre os indivíduos. Putnam (1996) dá um exemplo de membros participantes de associação de crédito rotativo, que chegam a prostituir suas filhas, como alternativa extrema para honrar seus compromissos, ou mesmo cometem suicídio em função do abalo moral que sofrerá caso não cumpra com sua obrigação. Nesta linha de raciocínio, quanto maior são os vínculos normativos entre os indivíduos, tanto maior é o capital social e menores são as chances para a ocorrência da transgressão ou deserção. Criam-se, assim, mecanismos reais para resolução de problemas próprios da ação em organizações, como os chamados comportamentos oportunistas.

Enfim, as discussões sobre capital social vêm mostrando a complexidade analítico-científica e prático-doutrinária para se implementar melhorias de vida em dada coletividade. Com esse debate, pretende-se sair do economicismo contraproducente e resgatar componentes fundamentais do desenvolvimento como o aspecto legal, político, educacional, informacional, ambiental e cultural. É um conceito que se encontra na fronteira entre o econômico, o cultural, o social e o político, uma vez que integra as noções de controle social, participação cidadã, cultura política, co-habitação, convivência, cultura cívica e outras. Portanto, o próprio conceito já traz consigo uma condição interdisciplinar para sua compreensão. E mais, além de analítico, compreensivo e explicativo a ideia de capital social é em si propositiva, uma vez que mostra claramente a íntima ralação entre organização, redes de confiança, eficiência social e desenvolvimento.

No contexto da gestão ambiental (conservação e uso dos recursos comuns) das UC, em particular das RESEX, observa-se um forte apelo

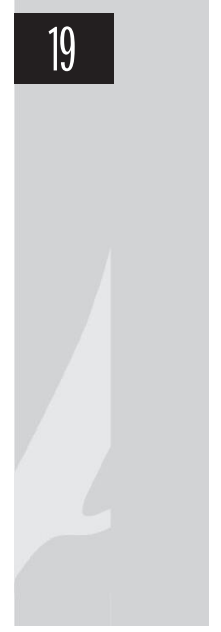


à participação comunitária por meio das organizações locais. Aliás, este aspecto constitui-se em diretriz que rege a Lei ${ }^{\circ}$ 9.985, de 18 de julho de 2000, que instituiu o Sistema Nacional de Unidades de Conservação da Natureza (SNUC), como se pode ler no excerto a seguir:

\section{Art. 5O SNUC será regido por diretrizes que: \\ [...] II - assegurem os mecanismos e procedimentos necessários ao envolvimento da sociedade no estabelecimento e na revisão da política nacional de unidades de conservação; III - assegurem a participação efetiva das populações locais na criação, implantação e gestão das unidades de conservação (grifo do autor) (BRASIL, 2000).}

Percebe-se deste modo o quanto é relevante o debate sobre as questões relacionadas às associações, seus problemas em nível práticoorganizacional, assim como as alternativas a partir do conceito de capital social.

A ideia central neste contexto é a de que a presença repressiva do Estado na vida prática das pessoas nessas áreas é contraproducente, pois os custos para a permanência e a manutenção de uma estrutura burocrático-repressiva nessas UCs inviabilizariam sua real efetivação. Por isso, o envolvimento das populações tradicionais nos processos de gestão é tido como algo imprescindível. Como bem atesta o biólogo José Márcio Ayres ${ }^{\circledR}$, citado por Silva (2006, p. 157):

Algumas pessoas ainda pensam que podem proteger as reservas somente com guardas, mas isso já se mostrou insuficientes. Um envolvimento mais amplo da população é necessário para

${ }^{2}$ Biólogo paraense que participou dos principais conselhos nacionais de conservação da biodiversidade. Foi membro de importantes associações científicas, (IUCN, ABC, NYZS, WCS) que por sua militância em favor da sustentabilidade do bioma amazônico brasileiro recebeu vários prêmios de instituições nacionais e internacionais. Contribuiu diretamente para a criação da Estação Ecológica Mamirauá (EEM), no estado do Amazonas, localizada entre as confluências dos rios Solimões e Japurá e o Auati-Paranã, com uma área total de 1.124.000 hectares. Em 1993, a EEM foi reconhecida pela Convenção Ramsar, passando a integrar uma relação de áreas úmidas de importância e interesse mundial. A iniciativa de criação da EEM foi apoiada por pesquisadores do Museu Emílio Goeldi (PA), da Universidade Federal do Pará (UFPA) e do Instituto Nacional de Pesquisas Amazônicas. A EEM foi transformada na primeira Reserva de Desenvolvimento Sustentável (RDS) do Brasil em 1996, também por iniciativa de Márcio Ayres e dos pesquisadores que o apoiavam. Márcio Ayres faleceu em 2003, vítima de câncer de pulmão (O INSTITUTO MAMIRAUÁ, 2012). 
a conservação ser um sucesso, além de investimento em longo prazo em saúde, educação e participação política.

Mas, como efetivar essa participação das comunidades ou de seus representantes em face dos problemas citados? Em que pese a existência de um marco legal bem estruturado acerca dos critérios e das normas para a criação, a implantação e a gestão de UC no Brasil, o que se deve fazer para motivar as populações tradicionais a se interessarem pelos processos formais, fazerem-se presentes nas reuniões, debates e proposições de maneira qualificada, ou seja, participem, tomem partido, tenham voz e vez?

As possíveis respostas para esses questionamentos precisam levar em consideração a construção de um projeto de qualificação das populações tradicionais, em que a educação escolar deve ser colocada como locomotiva desse processo. Mas essa educação escolar não poder ser aquela que vem sendo empregada hegemonicamente pelos sistemas educacionais de ensino, com um forte viés elitista, caracterizada por ser uma educação rural compensatória ${ }^{\natural}$, urbanocêntrica e metafísica, no sentido negativo do termo, ou seja, um conjunto de concepções desprovidas de conteúdo, fora da realidade vivida (JAPIASSU; MARCONDES, 1995).

Essa realidade educacional ideologizada, que tende à manutenção do status quo, pode ser perfeitamente observada na maioria das RESEX amazônicas, como no rio Cajari no sul amapaense, ou mesmo na RESEX Ipaú-Anilzinho, no rio Tocantins, município paraense de Baião (Figuras $1,2,3,4,5$ e 6 abaixo). De maneira preponderante, o que se observa nesses locais são escolas com instalações prediais carcomidas, professores mal formados e desmotivados, com salários aviltantes, presos ao poder

\footnotetext{
${ }^{3}$ A educação compensatória traz consigo uma concepção, a priori, extremamente preconceituosa, a saber: a pressuposição de que as populações tradicionais da Amazônia (índios, quilombolas, castanheiros, seringueiros, ribeirinhos etc.) possuem deficiências para aprender o que lhe é ensinado nas escolas, ou seja, elas não estariam suficientemente preparadas para tirar proveito satisfatório da escola. Ao colocar o peso da responsabilidade nas costas das próprias populações tradicionais, como se elas fossem culpadas pelos problemas educacionais, as elites políticas e estatais eximem-se de toda e qualquer culpabilidade pelas mazelas do ensino formal nos espaços campesinos brasileiros, estes tidos como atrasados, decadentes e subdesenvolvidos. Por isso, propõem uma educação elementar citadina que possa compensar as dificuldades de aprendizado, supostamente imanentes às pessoas que moram nas áreas não-urbanas. O resultado disso é a efetivação de uma educação pobre para pessoas pobres.
}

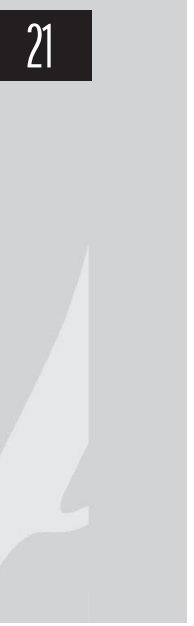


local e quase sozinhos, ou seja, sem apoio pedagógico capaz de oferecer aos docentes metodologias verdadeiramente transformadoras da realidade local (FREIRE, 1983; 2001; 2004; GADOTTI, 2008).

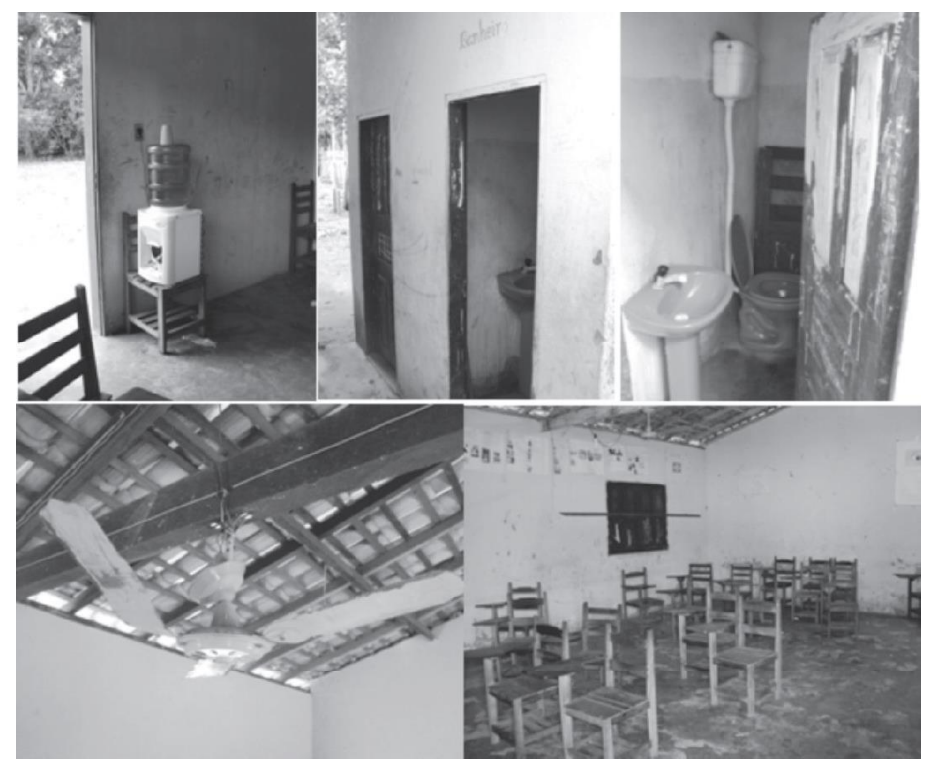

Figuras 1, 2,3,4 e 5: Imagens que denotam situações problemáticas das condições infraestruturais escolares na comunidade Joana Peres, RESEX Ipaú-Anilzinho. Foto: José B. da Silva, 2011.

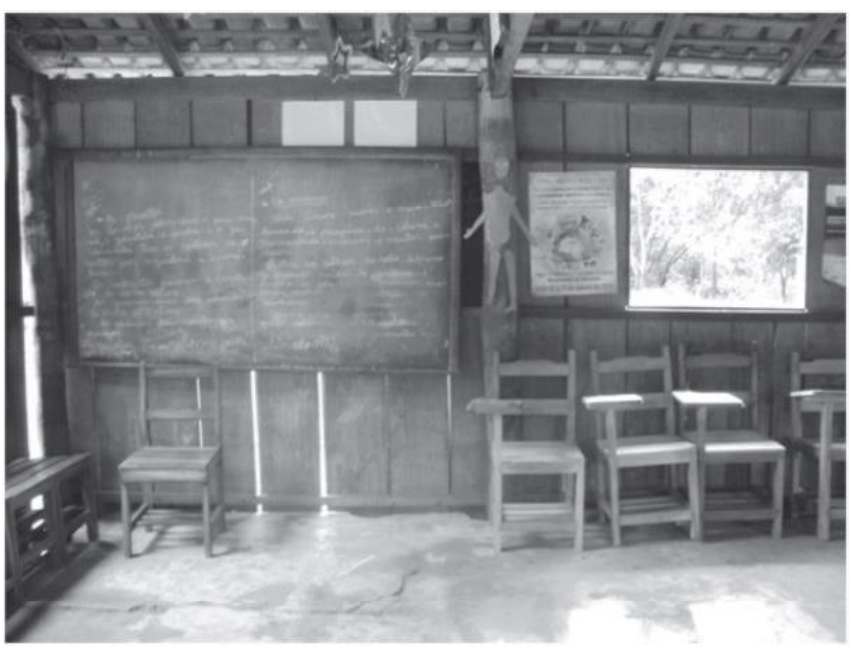

Figura 6: Sala de aula, comunidade Lucas, RESEX IpaúAnilzinho. Foto: José B. da Silva, 2011. 
Na verdade, a educação que se está reivindicando aqui é aquela que busca relacionar o conhecimento escolar com saber tradicional, que respeita as diferenças, afirma valores grupais e combate o individualismo, fomenta o capital social e a autoestima das pessoas, contribuindo para a construção de um indivíduo completo, que trabalha, participa com qualidade da vida social, organiza-se em associações e cooperativas, reivindica, propõe, enfim, que age dentro de uma ética da responsabilidade ${ }^{\circledR}$. Precisamente, uma educação formal que possa contribuir de maneira preponderante para a formação de sujeitos históricos, sejam eles crianças, adolescentes, jovens, adultos ou velhos.

A grande questão é exatamente saber como traduzir esta perspectiva de escola formal em prática educativa real transformadora. Neste particular, a educação do campo apresenta-se como um paradigma suscetível de gerar a sinergia imprescindível ao empoderamento ${ }^{\mathbb{B}}$ individual e coletivo das populações locais. Esse novo paradigma vem sendo implementado nos mais diversos espaços educacionais de ensino no Brasil e alhures, particularmente nas Casas Familiares Rurais (CFR) e Escolas Familiares Agrícolas (EFA), estas baseadas na metodologia da pedagogia da alternância.

As CFR e EFA brasileiras têm suas origens na França do início do século XX, onde se efetivou pela primeira vez as Maisons Familiales Rurales (REIS, 2011). Balizados pela pedagogia da alternância, esses espaços educativos podem ser colocados como um novo paradigma de educação formal que, dentre seus inúmeros objetivos, pode-se destacar a busca

\footnotetext{
${ }^{4}$ Weber (2006) distingue dois tipos ideais de ética no campo das relações sociais. A ética da convicção e a ética da responsabilidade. A primeira é aquela em que o indivíduo realiza sua conduta a partir de princípios ideológicos, de crenças e objetivos dos quais ele não abre mão ou que julga inalienáveis. Essa ética pode resultar no sectárismo ou no fundamentalismo. Por outro lado, o indivíduo que pratica uma ação balizada pela ética da responsabilidade caracteriza-se por ser uma pessoa que possui consciência das consequências de sua conduta e realmente sente na pele e na alma essa responsabilidade.

${ }^{5}$ Segundo Schiavo e Moreira (2005), uma pessoa empoderada significa dizer que ela obteve informações que lhe deram bases para a reflexão de sua condição atual e, por isso, é capaz de compreender seu presente e apontar as mudanças desejáveis no futuro. Precisamente, o empoderamento impulsionado pelo conhecimento provoca uma mudança de atitude das pessoas, grupos ou organização social para a ação prática, metódica e sistemática, no sentido dos objetivos e metas traçadas, abandonando-se a antiga postura meramente reativa ou receptiva.
}

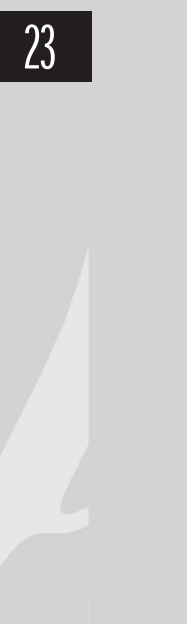


incessante pela articulação entre os processos formativos escolares e o mundo da vida dos educandos, em particular, o trabalho. Precisamente, é a tentativa de superação do modelo tradicional de educação, fortemente calcado em dicotomias seculares construídas no rastro da ciência moderna, a qual pretendeu separar o sujeito do objeto, a episteme da doxa, teoria da prática, o avançado do atrasado. Estas dicotomias, em verdade, serviram basicamente como discurso legitimador do poder e da dominação do moderno padrão de cientificidade inaugurado na Europa Ocidental dos séculos XVI e XVII (SANTOS, 2003).

Um exemplo alternativo e propositivo dessas dicotomias no Pará é a EFA de Marabá ${ }^{\natural}$. Com objetivo de oferecer educação escolar em nível de ensino fundamental e médio para filhos de agricultores familiares, esta escola trabalha alternadamente, e de maneira imbricada, um tempo próprio da/na escola e outro da/na comunidade. Partindo do ideário de que o processo educativo se dá em todas as esferas da vida humana, a EFA tem na pesquisa e no mundo do trabalho seus princípios pedagógicos fundamentais. Esses dois pressupostos do percurso formativo das crianças e dos jovens agricultores familiares são implementados dentro de um cenário escolar interdisciplinar e indutivo, ou seja, partindo da própria vivência dos alunos.

Ao colocar em suspeição a validade da dicotomia entre o trabalho manual e o intelectual, a EFA pretende valorizar a produção de bens materiais socialmente úteis, respeitando a produção da vida econômica dos educandos e ratificando que o lugar de formação também se dá no espaço do trabalho (CAPELO, 2011), sem preterir as práticas escolares. Em entrevista realizada com uma das monitoras da EFA de Marabá, podese perceber a maneira como essa escola busca realizar esse imbricamento entre o tempo escolar e o tempo comunitário. Para tanto, ela citou como exemplo o tema da migração.

[...] Nós aprendemos na escola tradicional que os hebreus migraram, que os japoneses migraram, que os italianos migraram. Mas, se formos parar para refletir sobre esse assunto, nós vamos ver que na Amazônia nossas famílias, nossos vizinhos, nós mesmos somos migrantes. Então no tempo escola nós vamos problematizar o termo migração, conceituá- 
lo, compreendê-lo através da música, de encenações, cordéis, [...]. Ainda no tempo escola os alunos irão preparar os roteiros de entrevista, observações $e$ registros que podem ser feitos de várias maneiras, como no caderno de campo, construção de croquis e assim captar informações sobre o processo real de chegada da sua família no local, perceber alterações na paisagem, rememorar a história de chegada de seus familiares, seus problemas $[\ldots]{ }^{6}$

É claro que trabalhar interdisciplinarmente, monitorar os educandos e suas produções nos dois tempos educativos (escola e comunidade), explorar diferentes formatos de expressão do conhecimento para buscar relacionar teoria com a prática, requer um esforço hercúleo de todos os sujeitos educacionais, em particular do professor, na construção de um novo paradigma educacional; e edificar paradigmas não é nada simples.

Como afirma Freire (2004, p. 48), o educador deve ser aquele componente importante no processo de construção do sujeito aprendente, que deve ser autônomo, crítico e reflexivo, porque questionador. $\mathrm{O}$ professor precisa ensinar seus educandos a "[...] pensar certo - e saber que ensinar não é transferir conhecimento, é fundamentalmente pensar certo - é uma postura exigente, difícil, às vezes penosa, que temos de assumir diante dos outros e com os outros, em face do mundo dos fatos, ante nós mesmos" (Grifo nosso).

\section{Notas conclusivas: para continuar debatendo}

Com base no que já foi exposto até o momento, pode-se concluir provisoriamente que não há como efetivar os objetivos concernentes ao desenvolvimento das RESEXs amazônicas (bem como em qualquer outra tipologia de proteção dos recursos naturais) sem um projeto de educação das populações locais. De fato, qualquer ideação na área do turismo, da piscicultura, do agro-extrativismo, associativismo, cooperativismo

${ }^{6}$ Entrevista realizada com uma Monitora em abril de 2010 no contexto da visita técnica na EFA de Marabá com alunos do programa Escola Ativa. 
etc. estará fadada ao fracasso, se esse plano não tiver em seu desenho um imbricamento imprescindível com um programa educacional das populações tradicionais. Todavia, essa educação precisa ser capaz de gerar nos sujeitos educacionais o empoderamento necessário à resolução de seus problemas individuais e grupais, em particular a questão da ação comunitária e o baixo capital social.

Por extensão, também não se protege os ecossistemas locais sem um projeto de proteção sociocultural das populações tradicionais, daí a importância de um educar para proteger. Precisamente, não se protege os territórios institucionalizados como UC unicamente por meio da fiscalização e da repressão, mesmo porque o Estado brasileiro não possui pessoal e estrutura logística capazes de cobrir em tempo real essas imensas áreas. Por isso, há a necessidade do envolvimento qualificado das populações locais no contexto da proteção dos espaços demarcados como UC. Mais uma vez faz-se necessário um projeto de educação emancipatória, capaz de gerar nas populações tradicionais a capacidade histórica para uma efetiva participação na conservação dos espaços naturais, e assim promover um desenvolvimento socialmente justo e ecologicamente sustentável.

Neste contexto, os educadores também possuem um papel importante e precisam estar aptos a refletir sobre suas práticas pedagógicas, sem perder de vista a busca constante pelo aperfeiçoamento do trabalho, em que a cada momento deve-se pretender fomentar a opção pelo melhor, não de modo assistemático e confuso, mas com procedimentos bem elaborados, com a confiança de que a busca pelo melhor é a grande utopia a alcançar e, assim, ter a esperança de que é possível uma educação mais humana e holística. É evidente que isso requer muita inspiração e, principalmente, transpiração, haja vista que empenho e vontade de produzir o novo requer esforços redobrados, mas sem jamais perder a ternura, o amor e a emoção de que se está fazendo a coisa certa (GADOTTI, 2008; FREIRE, 2001; 2004).

Essa caminhada utópica (no sentido positivo do termo) por mais longa que pareça ser somente alcançará seu desiderato se forem dados os passos certos neste sentido. As experiências são muitas, como é o caso das Casas Familiares Rurais e das Escolas Familiares Agrícolas, as quais implementam a metodologia da pedagogia da alternância e ancoram suas atividades pedagógicas em dois princípios básicos: a pesquisa, porque 
questiona, investiga, produz conhecimentos e reflexões; e o trabalho, porque é a condição de humanização das pessoas e produz saberes necessários à vida material e simbólica da coletividade. Como afirma Galeano (2007), a utopia é como que uma luz no fim do túnel, um ponto no infinito. Quanto mais se caminha, mais esse ponto fica distante. Então, "[...] Para que serve a utopia? Serve para isso: para caminhar" (GALEANO, 2007, p. 310).

\section{REFERÊNCIAS}

ABRAMOVAY, R. O capital social dos territórios: repensando o desenvolvimento territorial. In: Revista Economia Aplicada. v. 4, n. 2, abr/jun, São Paulo, 2000. p. 379-396.

BALÉE, W. Cultura na vegetação da Amazônia brasileira. In: NEVES, V. A. Biologia e Ecologia humana na Amazônia. Belém: Museu Emílio Goeldi, 1989, p. 95-109.

BRASIL. Lei no . 9.985, de 18 de julho de 2000. Regulamenta o Art. 225, $\int 1^{\circ}$, incisos I, II, III e VII da Constituição Federal, institui o Sistema Nacional de Unidades de Conservação da Natureza. Diário Oficial [da] República Federativa do Brasil, Poder Executivo, Brasília/DF, 18/07/2000.

CAPELO, F. de M. A formação em Alternância. Disponível: http: // wwww.batina.com/nanda/tese/teseI.htm. Acesso: 10/10/2011.

CARVAlhO, M. C. M. de (Org.). Construindo o saber. $3^{\mathrm{a}}$ ed. Campinas: Papirus, 1995.

COLEMAN, J. Foundations of Social Theory. Cambridge, Massachusetz: Harvard University Press, 1990.

CUNHA, M. C. da; ALMEIDA, M. W. B. Populações tradicionais e conservação ambiental. Revista Sociedade e Etnoconhecimento, 1999. p. 185-193.

D’ARAUJO, M. C. S. Amazônia e desenvolvimento à luz das políticas governamentais: a experiência dos anos 50. Revista Brasileira de Ciências Sociais. Rio de Janeiro, n. 19, jun., 1992. p. 40-55. 
DIEGUES, A. C. S. Mito moderno da natureza intocada. São Paulo: UCITEC/NUPAUB/SEC/USP, 1996.

Populações tradicionais em unidades de conservação: o mito moderno da natureza intocada. In: VIEIRA, P. F.; MAIMON, D. (Org.) As ciências sociais e a questão ambiental: rumo à interdisciplinaridade. Belém: APED/NAEA/UFPA, 1993, p. 219-249.

FREIRE, P. Educação como prática da liberdade. $17^{\text {a }}$ ed., Rio de Janeiro: Paz e Terra, 1983.

2001.

Pedagogia do Oprimido. $30^{\mathrm{a}}$ ed. Rio de Janeiro: Paz e Terra,

2004 .

Pedagogia da Autonomia. 15 ed. Rio de Janeiro: Paz e Terra,

GADOTTI, M. Boniteza de um sonho: Ensinar-e-aprender com sentido. São Paulo: Editora e Livraria Instituto Paulo Freire, 2008.

GALEANO, E. As palavras andantes. $5^{\mathrm{a}}$ ed. Porto Alegre: L\&PM, 2007.

GUERrA, A. J. T.; COElhO, M. C. N. (Org.). Unidades de conservação: abordagens e características geográficas. Rio de Janeiro: Bertrand Brasil, 2009.

JAPIASSU, H; MARCONDES, D. Dicionário de Filosofia. Rio de Janeiro: Jorge Zahar, 1995.

REIS, N. da S. Educação e alternância: notas para o debate social. Disponível: http://www.red-ler.org/educacao-alternancia-notas.pdf. Acesso: 02/04/2011.

O INSTITUTO MAMIRAUÁ. Márcio Ayres: a vida. Disponível em: http://mamiraua.org.br/institucional. Acesso em: 26/01/2012.

OSTROM. E. A behavioral approach to the regional choice theory of collective action. American Political Science Review, v. 92, n. 1, 1998. p. 01-22.

POSEY, D. A. Exploração da biodiversidade e do conhecimento indígena na América Latina: desafios à sobrevivência e a velha ordem. In: CAVALCANTI, C. (Org.). Meio ambiente, desenvolvimento 
sustentável e Políticas Públicas. São Paulo: Editora Cortez; Recife: Fundação Joaquim Nabuco, 1997, p. 345-368.

PUTNAM, R. D. Comunidade e democracia: a experiência da Itália moderna. Trad. de L. A. Monjardim, Rio de Janeiro: Fundação Getúlio Vargas, 1996.

RATTNER, H. Prioridade: construir o capital social, 2002. Disponível: $<$ www.abdl.org.br/rattner>. Acesso: 10/10/2004.

REIS, N. da S. Educação e alternância: notas para o debate social. Disponível: http://www.red-ler.org/educacao-alternancia-notas.pdf. Acesso: 02/04/2011.

ROUÉ, M. Novas perspectivas em Etnoecologia: "saberes tradicionais" e gestão dos recursos naturais. In: CASTRO, E.; PINTON, F. (Org.). Faces do trópico úmido: conceitos e novas questões sobre desenvolvimento e meio ambiente. Belém: Editora SEJUP/UFPA/NAEA, 1997. p. 201-217.

SANTOS, A. R. dos. Metodologia científica: a construção do conhecimento. $4^{\text {a }}$ ed. Rio de Janeiro: DP\&A Editora, 2001.

SANTOS, B. de S. Um discurso sobre as ciências. São Paulo: Cortez, 2003.

SCHIAVO, M. R.; MOREIRA, E. N. Glossário Social. Rio de Janeiro: Comunicarte, 2005.

SEVERINO, A. J. Metodologia do trabalho científico. $23^{\mathrm{a}}$ ed. São Paulo: Cortez, 2007.

SILVA, J. B. da. Sustentabilidade institucional e participação comunitária da Reserva Extrativista Rio Cajari. 2003. 149f. Dissertação de mestrado. Mestrado em Planejamento do Desenvolvimento/NAEA/UFPA. Belém: NAEA/UFPA, 2003 a.

Unidades de conservação e organizações de populações tradicionais sul-amapaenses: problemas, tendências e perspectivas. 2007. 377f. Tese de doutorado. Doutorado em Desenvolvimento SócioAmbiental/PDTU/NAEA/UFPA. Belém: NAEA/UFPA, 2007.

Elementos para a construção do sentido e o significado do conceito de população tradicional e sua importância para o século XXI. Revista de Humanidades do Curso de Ciências Sociais da UNIFAP. 
ISSN 1984 4352. n. 3, dez., Macapá, 2010. pp. 83-92. Disponível: http/ periodicos.unifap.br/index.php/pracs/article/download/153/137. Acesso: 07/04/2011.

SILVA, H. P. Saúde, conflitos ambientais e inclusão social: dinâmicas sócio-ecológicas em unidades de conservação na Amazônia e na Mata Atlântica. In: IRVING, Marta de Azevedo (Org.). Áreas Protegidas e Inclusão Social: construindo novos significados. Rio de Janeiro: Fundação Bio-Rio: Núcleo de Produção Editorial Aquarius, 2006, p. 157-168.

SILVA, M. F. da. Pensar o trabalho é pensar a vida: as dimensões da formação na pedagogia da alternância da Escola Família Agrícola de Marabá/PA. 2003. 103f. Dissertação de Mestrado. Mestrado em Agriculturas Familiares e Desenvolvimento Sustentável. Núcleo de Estudos Integrados sobre Agricultura Familiar/Universidade Federal do Pará. Belém: NEAF/UFPA, 2003b.

SIMONIAN, L. T. L. et al. Políticas públicas, desenvolvimento sustentável e recursos naturais em áreas de reservas na Amazônia brasileira. In: COELHO, M. C. N.; SIMONIAN, L. T. L.; FENZL, N. (Org.). Estado e políticas públicas na Amazônia: gestão de recursos naturais. Belém: CEJUP, 2000. p. 9-53.

Floresta Nacional do Amapá: breve histórico, políticas públicas e (in) sustentabilidade. Papers do NAEA. n. 167, ago., Belém, 2003.

TOCQUEVILle, A. de. A democracia na América. São Paulo: EDUSP, [1835] 1987.

WEBER, M. Ciência e política: duas vocações. São Paulo: Martin Claret, 2006.

30 Metodologia das ciências sociais. Trad. Augustin Wernert. São Paulo: Cortez; Campinas: Editora da Universidade de Campinas, 1993. pp. 9-20.

A dominação. Política e Sociedade. São Paulo, v.1, n. 2, 1996.

WOOLCOCK, M. Social Capital and Economic Development: Toward a Theoretical Synthesis and Policy Framework. In: Theory and Society, New York, v. 27, n. 2, 1998. p. 151-208. 